handball, ice hockey, football, floorball, basketball and automobile sports. The sport federations had their mandatory accidental insurance in the insurance company. The total numbers (no) of licensed athletes in each sport was provided from the Swedish Sports Confederation. Injury incidence as well as the proportion of injuries, at each body location was calculated. Severity of an injury was described as the degree of "permanent medical impairment” (PMI).

Results Highest injury incidence was in motorcycle and handball, followed by ice hockey, football, floorball, basketball and automobile sports. Lower limb was the most injured body location in all sports except in automobile sports (head/neck), motorcycle and ice hockey (upper limb). The proportion of lower limb injuries was higher for females in all sports. PMI was generally located in the lower limb but in motorcycle and automobile sports the upper limb was more prone to PMI. The most severe injuries was in motorcycle and automobile sports and located in the head/neck region.

Conclusions Popular sports with numerous of athletes and acute injuries must be the target for prevention actions at a national level. Lower limb were the most frequent injured body locations. The most severe PMI was in the head/neck location. Further studies should focus on more detailed information on injury types, anatomical locations and injury mechanisms to understand how to prevent these injuries and achieve greater safety in sport.

\section{THE EFFECT OF BODY CHECKING POLICY CHANGE ON CONTACT MECHANISMS IN 11-12 YEAR OLD ICE HOCKEY PLAYERS}

${ }^{1}$ German Martinez, 'Leticia Janzen, 'Maciek Krolikowski, 'Nicole Romanow, 'Luz PalaciosDerflingher, ${ }^{2}$ Claude Goulet, ${ }^{2}$ Luc Nadeau, ${ }^{1}$ Carolyn Emery. ${ }^{1}$ Sport Injury Prevention Research Centre, Faculty of Kinesiology, University of Calgary, Canada; ' ${ }^{2}$ Department of Physical Education, Faculty of Education, Laval University, Québec, Canada

\subsection{6/injuryprev-2016-042156.750}

Background Hockey Canada's evidence-based body checking (BC) policy change (2013) was informed by evidence that policy allowing BC in Pee Wee (11-12 year old) ice hockey players resulted in a $>3$-fold increased risk of injury and concussion compared with leagues where $\mathrm{BC}$ was not allowed.

Objective To compare the frequency of type and intensity of physical contacts (PC) and head contact in elite (upper 30\%) Pee Wee ice hockey games in leagues not allowing BC (2013-2014) compared with leagues allowing BC (2007-2008) using video analysis.

Methods Ten elite games pre-policy change (2007-2008) and 11 elite games post-policy change (2013-2014) were video recorded and analysed using a validated methodology to compare the frequency of type (trunk and other types of PC with limb/head/stick) and intensity (trunk contacts - level 1-5 intensity) of PC and head contact. Incidence rate ratios (IRR) were estimated using Poisson regression controlling for clustering by game) to compare PC before and after the BC policy change.

Results A total of 4409 trunk PCs and 2623 other PCs were observed. The total number of trunk PCs (IRR $=0.97,95 \% \mathrm{CI}$ : $0.83-1.14$ ) and other contacts (IRR $=0.87,95 \%$ CI: 0.59-1.29) did not change post-policy change. High intensity contacts (levels 4 and 5) were less frequent post-policy change $\left(\mathrm{IRR}_{4}=0.13\right.$, 95\% CI: $0.09-0.19$ and $\mathrm{IRR}_{5}=0.13$, 95\% CI: $\left.0.07-0.26\right)$ and low intensity contacts (level 2$)$ increased $\left(\mathrm{IRR}_{2}=1.47,95 \% \mathrm{CI}\right.$ : 1.21-1.79). Limb PCs decreased in 2013-14 (IRR $=0.48,95 \%$
CI; 0.33-0.71) and there was no difference for head contacts $(\mathrm{IRR}=0.81,95 \% \mathrm{CI}$; 0.51-1.30).

Conclusions There were no significant differences in total number of PC by study year. However, the incidence of high intensity (level 4-5) PCs decreased post -policy change. There was no significant difference in direct head contact or total number of other contacts. This will inform the development and evaluation of injury prevention and skill training strategies in youth ice hockey.

\section{Safety Management}

\section{Post Tue 2.15}

\section{TEXTING AND WALKING: A CONTROLLED FIELD STUDY OF CROSSING BEHAVIOURS AND INATTENTIONAL BLINDNESS IN TAIWAN}

Chih-Wei Pai" . Institute of Injury Prevention and Control, Taipei Medical University

\subsection{6/injuryprev-2016-042156.751}

Objective The paper investigates the effects of phone use (talking, texting, and listening to music) on the street-crossing behaviours of pedestrians and their inattentional blindness in Taiwan.

Background Recent handsets with touchscreens, as well as more advanced features including multimedia, and mobile applications (apps), exacerbate problems relating to cognitive distraction and reduced situation awareness.

Method A controlled field study using video cameras was conducted for observing pedestrians crossing behaviours (e.g., crossing time, sudden stops, looking both ways before crossing, disobeying traffic signals). Pedestrians were classified into two groups: experimental group (talking, texting, listening to music) and control group (no phone use). Pedestrians' inattentional blindness was examined by evaluating whether they saw an unusual object (i.e., a clown) nearby.

Results The results indicate that the proportions of unsafe crossing behaviours (e.g., sudden stops, disobeying traffic signals, not looking both ways before crossing) were higher among distracted individuals and more pronounced among those using instant-messaging apps. These instant-message app users were the least likely to see the clown, and music listeners were the least likely to hear the horn that the clown was honking. Contributing factors to unsafe behaviours include being a student, having a phone screen of 5 in. or larger, and having un-limited 3G Internet access.

Conclusions Texting message via apps was the leading factor on unsafe crossing behaviours of pedestrians and their inattentional blindness.

\section{2 PRIORITY ISSUES; SAFETY GUIDANCE TO PREVENT HEALTH PROBLEMS CAUSED BY POST NUCLEAR ACCIDENT RADIATION}

${ }^{1}$ Hiromi Kawasaki, ${ }^{1}$ Satoko Yamasaki, ${ }^{2}$ Mika Nishiyama, ${ }^{1}$ Masahiro Kawasaki, ${ }^{1}$ Mika Yuasa, ${ }^{3}$ Pete D'Angelo. 'Hiroshima University, Japan; 'Hiroshima Bunkyo Women's University, Japan; ${ }^{3}$ Doi Clinic, Japan

\subsection{6/injuryprev-2016-042156.752}

Background In 2011, following the nuclear accident in Fukushima, there were concerns about radiation. In particular, the complicated information related to air and soil, water and food. A great deal of confusing information can easily be found on the 
internet leaving residents uncertain and anxious. Clear and easy to understand safety guidelines should be made in order to prevent anxiety among residents.

Methods A questionnaire survey was conducted of mothers with 1-3 years old and junior high school students (15 years old) in Hiroshima. Junior high school students were included as they will be play an important role in future societies and their mothers showed high levels of anxiety regarding this issue.

Results 75 questionnaires were collected from mothers and 79 questionnaires were collected from junior high school students. 66 mothers answered "I was anxious about radiation", 67 answered "I am worried about radiation from food". Interestingly, 16 said "I know where I can acquire information about radiation" and 2 said "I know the limit of the annual dose of radioactivity". 65 Students answered "I am anxious about radiation" and "I am worried about radiation from food". 6 answered, "I know where I can acquire information about radiation".

Conclusions Although neither mothers nor students worried about the health effects of radiation, knowledge was insufficient. If a nuclear accident happens residents' confusion will occur in the same way as it did following the Fukushima accident. The goal of safety guidance considered areas such as, residents have a clear understanding of radiation and know the information source is reliable in helping them make decisions. Health educators provided a simple method to measure radiation in the air, soil, water and foods etc. and clarify the normal radiation dose as it relates to Sievert and Becquerel. Publication of clear, reliable information is essential.

\section{TRAINING ON SAFETY ASSESSMENT AND MANAGEMENT FOR NEW AND INNOVATIVE CHILDREN'S PRODUCTS}

${ }^{1}$ Karina Pernías, ${ }^{1}$ Mari Cruz Arenas, ${ }^{1}$ Mari Carmen Hita, ${ }^{2}$ Dario Gregori, ${ }^{2}$ Giulia Lorenzoni, ${ }^{3}$ Helena Menezes, ${ }^{4}$ Pedro A Pernías. ${ }^{1}$ AIJU Technological Institute for Children'S Products and Leisure, Spain; ${ }^{2}$ Unit of Biostatistics, Epidemiology and Public Health, Department of Cardiac, Thoracic and Vascular Sciences, University of Padua, Italy; ${ }^{3}$ ANEC, the European Consumer Voice in Standardisation, Belgium; ${ }^{4}$ Universidad De Alicante, Departamento De Lenguajes Y Sistemas Informáticos, Spain

\subsection{6/injuryprev-2016-042156.753}

Background The children's products industry is forced to innovate continuously in order to maintain the business activity and meet the highest safety requirements, taking into account the special vulnerability of children as consumers. The SMEs which stand for $95 \%$ of total of this industry lack of resources and knowledge to assess the safety of their new products, which undermines their competitiveness. Similarly, consumer associations are the other weak stakeholder. According to the Regulation of the European Parliament and the Council on a Consumer Programme 2014-2020, one of the main issues to be addressed is the insufficient capacity of consumer organisations, especially the lack of resources and specialists, in the new Member States in particular.

Objective To develop and implement an innovative Open Educational Resource using ICT-based methodologies in order to provide training on safety assessment and management for new and innovative children's products customised to the needs of the staff working in the industry, consumer organisations and other stakeholders.

Results The result has been an online course with unlimited participation and free and open access via the Internet, commonly known as MOOC (Massive Open Online Course), on children's product safety. Its pedagogical design is focused on five key areas: learning, activities, resources, interactivity and assessment. It covers subjects such as the legal framework for children's products, risk analysis and epidemiology of the injuries related to products used by children.

Conclusions In addition to training, this MOOC has also served as a platform to exchange experience and raise awareness of the importance of safety products for children among the key stakeholders (consumers, industry and other stakeholders). MOOCs aimed at specific interest groups actively involved in product safety can become an effective tool to prevent unintentional injuries that arise from the use of products.

\section{FARM MAPPING TO ASSIST, PROTECT, AND PREPARE EMERGENCY RESPONDERS (FARM MAPPER)}

${ }^{1}$ Matthew Keifer, ${ }^{1}$ Bryan Weichelt, ${ }^{2}$ Gerald Minor, ${ }^{1}$ Iris Reyes, ${ }^{1}$ Casper Bendixsen. ${ }^{1}$ National Farm Medicine Centre, Marshfield Clinic Research Foundation, Marshfield, WI, USA, 2Pittsville Fire Department, Pittsville, WI, USA

\subsection{6/injuryprev-2016-042156.754}

Background Farm Mapping to Assist, Protect and Prepare Emergency Responders (Farm MAPPER) is an interactive web-based tool developed by the NFMC that provides emergency responders onsite information about hazards, resources and physical layouts of agricultural operations. Emergency responders generally do not have right of entry to private farms to map them for future emergencies. Farm MAPPER provides a palate of icons representing items important in emergency events such hazards, access points, water sources, etc., even information on special needs farm residents.

Methods The system was developed to allow a farmer to drag and drops icons on an overhead farm map using their computer. Through Farm MAPPER this information is accessible to emergency responders in the fire station, in-route by web connected device, or onsite using QR codes located on post box posts. This knowledge assists responders to efficiently and safely respond to on farm emergencies. MAPPER presently displays icons on Bing maps in an overhead bird's eye view of the farm.

Results The team developed and tested the prototype Farm MAPPER application with local farmers and conducted mock response with the Pittsville fire department using the MAPPER on a volunteer farms. Feedback was received from both groups. Farmers found it easy to use and expressed willingness to map their farms for the benefit of the emergency responders who might use the application. Emergency responders who participated in the mock responses found the application helpful in quickly locating the items that they needed to avoid or employ for their safety and response efficiency. They suggested modifications to the application which have since been incorporated.

Conclusions The system was developed to handle geographic diversity, and will be available for worldwide adoption. The team is currently seeking collaborative opportunities to further expand the project reach beyond central Wisconsin.

\section{HOW COULD ROAD SAFETY FUNDING BE EFFECTIVE?}

Arumdyah Widiati, Harry Evdorides. University of Birmingham, United Kingdom 